\title{
Between concrete and abstract: the Malaysian chinese way of naming dishes
}

\begin{abstract}
The Chinese pay considerable attention to the naming of dishes. While coming up with a wellprepared cuisine is considered as an artwork, giving it a suitable name is no different from adding the touch that brings a work of art to life. In naming a dish, the community utilizes its linguistic and non-linguistic resources. Dish names are hence a group of living fossils supporting the notion of language reflecting society. Using 1077 samples of dish names collected from Malaysian Chinese weddings and the lunar new year celebration, the present paper aims to investigate the concrete and abstract naming of Chinese dishes, and discuss the common cultural considerations underlying them. It was found that concrete naming deals with the tangible aspects of a dish by incorporating method of preparation, taste/aroma, appearance of dish, as well as container used; while abstract naming draws support from four-character idioms, legends/historical events, auspicious words, Chinese auspicious objects and legendary animals, and homophones, with cultural considerations playing a major if not the sole role in it.
\end{abstract}

